\title{
Justicia constitucional y democracia: Sello de constitucionalidad en el control preventivo obligatorio (Tribunal Constitucional)
}

\author{
Comentario de Felipe Ignacio Paredes Paredes
}

Santiago, diecisiete de marzo de dos mil once.

\section{VISTOS Y CONSIDERANDO:}

Primero.- Que, por oficio No 9344, de 10 de marzo de 2011, la Cámara de Diputados ha enviado el proyecto de ley, aprobado por el Congreso Nacional, Boletín $\mathrm{N}^{\circ} 3.778-18$, que tipifica el delito de tráfico de niños y personas adultas y establece normas para su prevención y más efectiva persecución criminal, a fin de que este Tribunal, en conformidad a lo dispuesto en el artículo 93, inciso primero, $\mathrm{N}^{\circ} 1$, de la Constitución Política de la República, ejerza el control de constitucionalidad respecto del número 4 de su artículo primero, que introduce el artículo 411 octies al Código Penal, y del número 1 de su artículo segundo, que introduce el artículo 78 bis al Código Procesal Penal;

SEgundo.- Que el artículo 93, inciso primero, $\mathrm{N}^{\circ} 1^{\circ}$, de la Constitución Política establece que es atribución de este Tribunal ejercer el control de constitucionalidad de las leyes orgánicas constitucionales antes de su promulgación;

Tercero.- Que el artículo 77, incisos primero y segundo, de la Carta Fundamental señala:

"Una ley orgánica constitucional determinará la organización y atribuciones de los tribunales que fueren necesarios para la pronta y cumplida administración de justicia en todo el territorio de la República. La misma ley señalará las calidades que respectivamente deban tener los jueces y el número de años que deban haber ejercido la profesión de abogado las personas que fueren nombradas ministros de Corte o jueces letrados.

La ley orgánica constitucional relativa a la organización y atribuciones de los tribunales, sólo podrá ser modificada oyendo previamente a la Corte Suprema de conformidad a lo establecido en la ley orgánica constitucional respectiva.";

A su vez, el artículo 84, inciso primero, de la Carta Fundamental dispone:

"Una ley orgánica constitucional determinará la organización y atribuciones del Ministerio Público, señalará las calidades y requisitos que deberán tener y cumplir los fiscales para su 
nombramiento y las causales de remoción de los fiscales adjuntos, en lo no contemplado en la Constitución. Las personas que sean designadas fiscales no podrán tener impedimento alguno que las inhabilite para desempeñar el cargo de juez. Los fiscales regionales y adjuntos cesarán en su cargo al cumplir 75 años de edad".

CuArto.- Que las disposiciones del proyecto sometidas a control preventivo de constitucionalidad establecen:

"Artículo 411 octies. - Previa autorización del juez de garantía competente, el fiscal podrá autorizar, en las investigaciones por los delitos previstos en el presente párrafo, que funcionarios policiales se desempeñen como agentes encubiertos $y$, a propuesta de dichos funcionarios, que determinados informantes de esos servicios actúen en esa calidad.

Cuando existieren sospechas fundadas de que una persona o una organización delictiva bubiere cometido o preparado la comisión de alguno de los delitos indicados en este párrafo, y la investigación lo hiciere imprescindible, el tribunal, a petición del Ministerio Público, podrá autorizar la interceptación o grabación de las telecomunicaciones de esa persona o de quienes integraren dicha organización, la fotografía, filmación u otros medios de reproducción de imágenes conducentes al esclarecimiento de los hechos y la grabación de comunicaciones. En lo demás, se estará integramente a lo dispuesto en los artículos 222 a 225 del Código Procesal Penal.

Estas técnicas podrán ser utilizadas por el fiscal sea que se trate de una persona, un grupo de personas o una organización delictiva que bubiere cometido o preparado la comisión de los delitos señalados en este artículo.

En todo aquello no regulado por este artículo los agentes encubiertos e informantes se regirán por las disposiciones respectivas de la Ley $N^{\circ} 20.000 . "$. $\ldots$

"Artículo 78 bis. - Protección de la integridad física y psicológica de las personas objeto del tráfico ilícito de migrantes y víctimas de trata de personas. El Ministerio Público adoptará las medidas necesarias, o las solicitará, en su caso, tendientes a asegurar la protección de las víctimas de estos delitos durante el proceso penal, teniendo presente la especial condición de vulnerabilidad que las afecta.

Cuando se trate de menores de dieciocho años, los servicios públicos a cargo de la protección de la infancia y la adolescencia deberán facilitar su acceso a las prestaciones especializadas que requieran, especialmente, aquellas tendientes a su recuperación integral y a la revinculación familiar, si fuere procedente de acuerdo al interés superior del menor de edad.

En los casos en que las víctimas de los delitos establecidos en los artículos 411 bis y 411 quáter del Código Penal carezcan de representante legal o cuando, por motivos fundados, el juez estime que los intereses de las personas menores de edad son independientes o contradictorios con los de aquel a quien corresponda representarlo, el juez le designará un curador ad litem de cualquier institución que se dedique a la defensa, promoción o protección de los derechos de la infancia".; 
Quinto.- Que, de acuerdo al considerando segundo de esta sentencia, corresponde a este Tribunal pronunciarse sobre las normas del proyecto remitido que están comprendidas en las materias que el Constituyente ha reservado a una ley orgánica constitucional;

Sexto.- Que las disposiciones sometidas a control, ya transcritas, al conferir nuevas atribuciones a los Juzgados de Garantía y al Ministerio Público, son propias de las leyes orgánicas constitucionales a que aluden los artículos 77, incisos primero y segundo, y 84 , inciso primero, de la Constitución Política;

SÉPTimo.- Que consta de los antecedentes que se ha dado cumplimiento a lo dispuesto en el artículo 77, inciso segundo, de la Carta Fundamental;

OctAvo.- Que, de igual forma, consta en los autos que las normas sometidas a control, han sido aprobadas en ambas Cámaras del Congreso Nacional con las mayorías requeridas por el inciso segundo del artículo 66 de la Constitución y que sobre ella no se ha suscitado cuestión de constitucionalidad;

Noveno.- Que el artículo 411 octies que se introduce al Código Penal, propuesto en el número 4 del artículo primero del proyecto de ley sometido a control, y el artículo 78 bis que agrega al Código Procesal Penal, propuesto en el número 1 de su artículo segundo, no son contrarios a la Constitución Política de la República.

Y VISTO lo prescrito en los artículos 66 , inciso segundo, 77 , incisos primero y segundo, 84, inciso primero, 93, inciso primero $\mathrm{N}^{\circ} 1^{\circ}$ e inciso segundo, de la Constitución Política de la República y lo dispuesto en los artículos 34 a 37 de la Ley Orgánica Constitucional del Tribunal Constitucional,

SE DECLARA: Que el artículo 411 octies que se introduce al Código Penal, propuesto en el número 4 del artículo primero del proyecto de ley sometido a control, y el artículo 78 bis que agrega al Código Procesal Penal, propuesto en el número 1 de su artículo segundo, no son contrarios a la Constitución Política de la República.

Devuélvase el proyecto a la Cámara de Diputados, rubricado en cada una de sus hojas por la Secretaria del Tribunal, oficiándose al efecto.

Regístrese, déjese fotocopia del proyecto y archívese.

Redactaron la sentencia los Ministros que la suscriben.

Rol No 1939-2011-CPR. 


\section{COMENTARio}

\section{La objeción democrática y nuestro Tribunal Constitucional}

Una de las cuestiones más espinosas del Derecho constitucional de hoy y de siempre es la tensión existente entre justicia constitucional y democracia. El debate en Chile ha sido escaso ${ }^{1}$, no obstante, se trata de una discusión que en otros países es congénita al nacimiento de la figura de la revisión judicial de las leyes ${ }^{2}$. Es ésta de una polémica sin solución, donde han intervenido muchos de los más ilustres constitucionalistas y teóricos del Derecho de la historia: Hamilton, Kelsen, Schmitt, Ely, Dworkin, etc., solo por citar algunos. Sin embargo, aún se está lejos de llegar a un consenso.

Como sea, una cuestión es clara: la objeción existe y aun cuando creamos en la necesidad de que el legislador deba ser controlado por la justicia constitucional, debemos preocuparnos por ella. Salvo, claro está, que no atribuyamos mayor valor a la democracia como forma de gobierno. En esto no debe haber misterio, no pocas veces en nuestro ordenamiento jurídico existen principios que entran en contradicción y que igualmente son dignos de protección. Por lo mismo, armonizar su aplicación y minimizar el conflicto es un imperativo para todos los operadores jurídicos.

En este sentido, no es irrelevante la configuración del sistema de justicia constitucional. En efecto, habrá determinados diseños en donde la objeción contramayoritaria se haga más patente que en otros. Desde luego, uno de los factores que contribuye a aumentar los problemas de legitimidad de la jurisdicción constitucional son justamente, las atribuciones que se le conceden. De esta manera, a mayores atribuciones, mayores son las posibilidades de que ésta entre en conflicto con el legislador. Es pacífico que el Tribunal Constitucional chileno posee un "vigoroso poder de control de constitucionalidad" . Por lo mismo, desde el punto de vista del respeto a la regla de la mayoría, hay que tomar con mesura la idea de dotarle con nuevas atribuciones, o incluso, interpretar extensivamente las que ya tiene.

${ }^{1}$ Con las excepciones de Atria y Zapata. Respecto del primero, véanse: Atria, F., "El Tribunal Constitucional y la objeción democrática”, en Revista Chilena de Derecho, Vol. 20 núms. 2-3, tomo I (1993), pp. 367-378; Atria, F., "Revisión judicial: el síndrome de la víctima insatisfecha”, en Estudios Públicos, núm. 79 (2009), pp. 347-402; Atria, F., "Inaplicabilidad y coherencia: contra la ideología del legalismo", en Revista de Derecho UACh, Vol. 12 (2001), pp. 2001. Sobre el segundo, véase: Zapata, P., Justicia Constitucional. Teoría y Práctica en el Derecho comparado, Editorial Jurídica de Chile, Santiago (2008), passim.

${ }^{2}$ Una buena introducción al tema, tanto por la perspectiva general que ofrece como por lo representativo de la bibliografía citada, puede verse en: Bellamy, R. y Castiglione, D., "Constitutionalism and Democracy - Political Theory and the American Constitution”, en British Journal of Political Science, Vol. 27, núm. 4 (1997), pp. 595-618.

${ }^{3}$ Gómez, G., "La reforma constitucional a la jurisdicción constitucional", en Zúñiga, F., Reforma Constitucional, LexisNexis, Santiago (2005), p. 668 (651-684). 


\section{El denominado "sello de constitucionalidad"}

Un sector de la doctrina ha criticado el efecto que producen las sentencias del Tribunal Constitucional cuando éste ejerce el control preventivo, en virtud de las atribuciones consagradas en los artículos $93 \mathrm{~N}^{\circ} 1$ y $93 \mathrm{~N}^{\circ} 3$ de la Constitución. Dicho efecto, que se ha denominado "el sello de constitucionalidad" ${ }^{4}$, se encuentra establecido en los artículos 51 inciso $2^{\circ}$ y 71 de la Ley Orgánica del Tribunal Constitucional y, en términos generales, consiste en que una vez pronunciado el Tribunal Constitucional en el ejercicio del control a priori, que un precepto legal es constitucional, no podrá volver a ser discutida la constitucionalidad de ese precepto con carácter ex post. No discutiremos aquí acerca de las ventajas y desventajas de la existencia del control previo de constitucionalidad. Partiremos de la base de que la Constitución lo establece claramente. Esto nos pone en la necesidad de racionalizarlo, de modo de hacerlo lo más compatible posible con el principio democrático.

Pues bien, el denominado "sello de constitucionalidad", que no es otra cosa que lo que antiguamente se denominaba efecto de cosa juzgada de la sentencia constitucional ${ }^{5}$, plantea indudablemente una serie de problemas. A nuestro juicio, los más relevantes traen causa en el control preventivo obligatorio del artículo $93 \mathrm{~N}^{\circ} 1$ de la Constitución. Precisamente, sobre ello versa la sentencia de marras.

En la especie, el Tribunal Constitucional procede a controlar la constitucionalidad del entonces proyecto de ley que tipifica el delito de tráfico de niños y personas adultas y establece normas para su prevención y más efectiva persecución criminal, posteriormente publicada como ley de la República, con el número 20.507. En concreto, respecto de dicho cuerpo legal, el Tribunal Constitucional solamente ejerce el control sobre el artículo $1 \mathrm{~N}^{\circ}$ 4, que introduce el artículo 411 octies al Código Penal, y del número 1 de su artículo segundo, que introduce el artículo 78 bis al Código Procesal Penal. El primero de ellos introduce la figura del agente encubierto para este tipo de delitos. El segundo, concede al Ministerio Público determinadas prerrogativas para proteger a las víctimas de dichos delitos.

Como se puede observar, aparentemente el estándar de control que utiliza el tribunal no es de lo más riguroso. En efecto, simplemente se limita a constatar que la referida materia es de aquellas que deben ser reguladas mediante una ley orgánica constitucional (considerandos $2^{\circ}$ al $8^{\circ}$ ). Establecido lo anterior, señala sin dar mayores argumentos que las disposiciones controladas son conformes a la Constitución (considerando $9^{\circ}$ ). De un rápido examen, se puede constatar que esta es una práctica frecuente de nuestro Tribunal Constitucional: cuando ejerce el control obligatorio y considera que la disposición de que se trate es constitucional, simplemente se limita a afirmarlo, y casi nunca

${ }^{4}$ Verdugo, S., "El sello de constitucionalidad de los preceptos legales declarados constitucionales en el control preventivo”, en Revista de Derecho y Ciencias Penales, núm. 13 (2009), pp. 57-81, passim.

${ }^{5}$ Verdugo, M. et al., Derecho Constitucional, tomo II, $2^{\text {a }}$ ed. Editorial Jurídica de Chile (1999), p. 301 . 
ofrece razones en tal sentido ${ }^{6}$. Es en este contexto donde se plantea el debate acerca del "referido sello de constitucionalidad.

La polémica se suscita es este caso, debido a que el Tribunal Constitucional normalmente no señala expresamente cuál es el vicio. Esto impediría cualquier tipo de control ulterior de constitucionalidad respecto de esa norma. En concreto, impediría deducir respecto de dichos preceptos legales la acción de inaplicabilidad consagrada en el artículo 93 N $^{\circ} 6$ de la Carta Fundamental. Así las cosas, según Verdugo, "se estaría impidiendo la declaración de un control represivo respecto de dicha norma, dejando a las personas en una eventual indefensión frente al legislador" 7 .

De todos modos, se debe reconocer que la redacción que poseen los artículos $51 \mathrm{y}$ 71 de la Ley Orgánica Constitucional del Tribunal Constitucional es poco feliz. Dichos preceptos hablan de "vicio", lo que constituye una impropiedad del lenguaje. La razón es que, si el Tribunal Constitucional estima que la norma controlada es constitucional, es porque precisamente no adolece de ningún vicio. Si por el contrario considera que el precepto posee algún vicio de constitucionalidad, así lo declarará (suponemos fundadamente) y, por tanto, la norma no entrará en vigencia y el problema no se producirá. En este sentido, habría sido más acertado hablar de "el mismo motivo".

Sin perjuicio de ello, la tesis en comento es aún más atrevida, y en definitiva, plantea que los citados artículos son inconstitucionales e inconvenientes. Con respecto a lo primero, el argumento sería que dotar de efectos generales a las sentencias del Tribunal Constitucional impone un requisito adicional a los que establece Constitución en su artículo $93 \mathrm{~N}^{\circ}$ 6. Este argumento es falaz, pues justamente la función de las leyes orgánicas constitucionales es desarrollar los preceptos constitucionales, regulando las bases esenciales de un órgano o un régimen especial dentro del marco general de la Constitución. En este sentido, "se trata de textos legislativos cuyo propósito es el funcionamiento o la organización de los poderes públicos a partir de las normas enunciadas

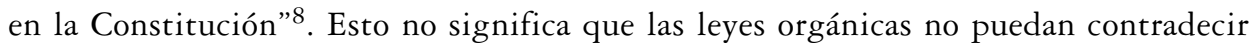
la Constitución, pero tampoco significa que deban limitarse a reproducir los preceptos constitucionales. En este marco, es la misma Constitución que habilita al legislador orgánico en su artículo 92 para regular el procedimiento que permita poner en práctica las atribuciones del artículo 93, y entendemos que los efectos de las sentencias es una cuestión eminentemente procesal, que en consecuencia no representa ningún problema de constitucionalidad.

Es más, en el sistema francés, el más parecido al nuestro que existe en Derecho comparado, existen disposiciones bastante similares a las de la ley orgánica chilena. Teniendo en cuenta, que al igual que en nuestro país, el artículo 61-1 de la Constitución de 1958, donde se regula la cuestión prioritaria de constitucionalidad, habilita al legislador orgánico para determinar las condiciones de aplicación de dicha atribución del Consejo

\footnotetext{
${ }^{6}$ Véanse a título ejemplar los roles: 1891-2011, 1898-2011, 1901-2011, etc.

${ }^{7}$ Verdugo, S., ob. cit., p. 77.

${ }^{8}$ Meny, Y., "El proceso legislativo en Francia”, en Revista Española de Derecho Constitucional, núm. 16
} (1986), pp. 163-164. 
Constitucional. Por otra parte, el artículo 23-2 de la Ley Orgánica No 2009-1523 de 10 de diciembre señala que no se podrá interponer cuestión prioritaria de constitucionalidad si ella ya ha sido declarada constitucional por el Consejo Constitucional, por los mismos motivos, salvo cambio en las circunstancias. La cuestión es que en Francia, al menos hasta la fecha, a ningún autor se le ha ocurrido señalar que dicha disposición es inconstitucional. Por el contrario, se la ha justificado con el objeto de "preservar la autoridad de las decisiones del Consejo Constitucional en el marco del control a priori"”.

\section{La conveniencia de que las sentencias constitucionales produzcan efectos generales}

Cuestión distinta es la conveniencia de que exista una disposición de estas características. En este sentido, el argumento más obvio es que existe un objetivo al que todo sistema de justicia constitucional debe propender: la unidad y coherencia en la interpretación constitucional. Por esta razón, es altamente contraproducente para el buen funcionamiento del sistema que a los ciudadanos se nos diga en una primera oportunidad que la norma en cuestión es constitucional y luego se nos diga lo contrario.

Frente a esto se podría replicar que, como la misión del Tribunal Constitucional es asegurar el principio de supremacía constitucional, debe contar con la mayor cantidad de atribuciones que le permitan, por ejemplo, poder remediar los errores que cometa en el ejercicio de dicha actividad. Desde este punto de vista, sería conveniente que pudiera contar con una segunda oportunidad para revisar la constitucionalidad de la ley.

Sin embargo, este argumento debe ceder ante el hecho incontrastable de que la actividad de la justicia constitucional no es gratuita y produce inevitables costos para el principio democrático y, por tanto, se debería racionalizar su ejercicio en la medida de lo posible. Así las cosas, dotar de efectos permanentes a la sentencia constitucional parece la alternativa más sensata. Es de sentido común que, si por ejemplo, está comprobado que fumar produce cáncer, cuanto menos fumemos, menos posibilidades tendremos de desarrollar dicha enfermedad. De igual modo, si cada vez que el Tribunal Constitucional anula una norma emanada de los representantes del cuerpo político estamos sacrificando el principio democrático, sería mejor que la posibilidad de controlar al legislador se ejerciera por una única vez. Lo contrario sería poner a las decisiones de la mayoría política bajo constante sospecha, o lo que es lo mismo, olvidarnos de que la ley posee una "cierta dignidad", por el hecho de que permite resolver nuestros desacuerdos sobre la base de un procedimiento que excluye la violencia y considera la participación de todos los ciudadanos en igualdad de condiciones ${ }^{10}$.

Lo anterior exige, eso sí, que el Tribunal Constitucional adopte la mayor diligencia en el ejercicio del control a priori. Resulta evidente que no se le puede exigir que explique en la sentencia por qué la norma en cuestión no contradice cada uno de los 129 artículos de la Constitución. De todos modos, esto no excluye que a la hora de realizar

\footnotetext{
${ }^{9}$ Rousseau, D., Droit du contentieux constitutionnel, 9a edición, Montchrestien, Paris (2010) p. 246.

${ }^{10}$ Cfr. Waldrom. J., Derecho y desacuerdos, Marcial Pons, Madrid (2005), p. 131.
} 
el ejercicio de comparación entre dicha norma y el texto de la Carta Fundamental los jueces de dicho tribunal sí se representen, al menos mentalmente, cada uno de los posibles artículos que podrían entrar en conflicto, y luego de un razonado análisis concluir que en definitiva la antinomia no existe.

Si las cosas suceden de esta manera, no hay razón alguna para temer que el Tribunal Constitucional, como en el considerando $9^{\circ}$ de esta sentencia, se limite a señalar que los preceptos controlados "no son contrarios a la Constitución Política de la República". Por el contrario, estamos dando cumplimiento a uno de los imperativos básicos de la democracia constitucional, donde los poderes están limitados, pero donde, a la vez, también es importante la opinión de la mayoría política. Puede que, no obstante lo anterior, se diga que sea probable que en la práctica esta descripción no se ajuste a la realidad y que nuestro Tribunal Constitucional no pocas veces haya sido poco prolijo en su análisis. No obstante, ello ya es harina de otro costal y excede las posibilidades de este análisis. 